\title{
Erobots and the deterritorialization of eroticism
}

\author{
Aura-Elena Schussler* \\ "Babeş-Bolyai" University, Romania
}

\begin{abstract}
As a result of its accelerated evolution in the early $21^{\text {st }}$ Century, technology has already extended far beyond mere instrumental status. In the not too distant future we can expect technology to move towards a new dimension in terms of fusing with human nature; most notably in the field of intimacy towards what are known as erobots (i.e., sexbots, augmented erotic characters, erotic chatbots, erotic avatars, etc.). Given that these erobots have every chance to become part of a future eroticism, this places erobots beyond the onto-metaphysical grounding of the Western tradition regarding objects. This is an aspect that attracts the dissolution of the anthropocentric legacy of Western metaphysics, within the parameters of OOO, by showing that, in this paradigm, so-called human uniqueness is suffering an ontological twist. To show this I am investigating, the scenario that involves the relationship between a sexbot and a human, alongside of that between two sexbots, within the limits of OOO. Consequently, I am addressing the issue of how a sexbot relates to both a human agent and to another sexbot. I am also analyzing the perspective in which a future presence of erobots in the intimate life of the individual will twist the traditional image of eroticism in Western culture. This perspective is opening a deconstructing process with regard to human exceptionalism - analyzed within the limits of the 'deterritorialization' of eroticism - from the traditional structures of Western metaphysical heritage. Such deterritorialization emphasizes the paradigm shift in which eroticism is leaving the familiar terrain of the metaphysics of presence and the fixed structures of societies' 'strata'. Thus, following the philosophical thinking of Gilles Deleuze and Félix Guattari, the 'reterritorialization' of eroticism - in the fluid, transversal and rhizomatic network of technology - is an ongoing, ever-changing process, taking place in the immanent sphere of techno-eroticism's 'plane of consistency'.
\end{abstract}

Keywords: 'Erobots', sexbots, eroticism, 'deterritorialization', 'real objects', 'sensual objects'

\section{INTRODUCTION}

Seen as being inherited from ancient Greek philosophy, eroticism remains, in the general common sense of the Western tradition, a passionate form of love, placed over time under the auspices of heterosexual love. This predominance of heteronormativity is not only the consequence of the JudeoChristian legacy but also of the first industrialisation and later the Victorian Era. The latter is a period well known for the imposition of a more rigid social order in the erotic field, which led to a divergence between internalised coercive social norms and subjective impulses. As Foucault claims, the Victorian Era witnessed a paradigm shift from the ancient reminiscences of ars erotica to the modern flourishing of scientia sexualis or, to put it another way, from the knowledge/art of sensual pleasures and eroticism (ars erotica) to the institutionalised paradigm of scientia sexualis (Foucault, 1990). The latter took place under the auspices of the 'confessional apparatus' and the scientific inquiry of medicine and psychoanalysis (Foucault, 1990) that gave birth to the social 'strata' of eroticism (Deleuze \& Guattari, 2005). This erotic strata is nothing more than the hierarchical mechanism of division between ars erotica and scientia sexualis, starting in the $19^{\text {th }}$ Century. Within these limits scientia sexualis stratified and channelled the flow of eroticism towards the paternalistic and universally-valid norms of sexuality. Prior to these aspects, passionate love - pertaining mostly to $19^{\text {th }}$ century Romanticism -

\footnotetext{
*Associate Lecturer, Department of Philosophy, Faculty of History and Philosophy, "Babeş-Bolyai" University, 1 Mihail Kogălniceanu Street, Cluj-Napoca, 400084, Romania. E-mails: aursch2005@yahoo.com, aura.schussler@ubbcluj.ro. 2589-9953 @ 2022 - The authors. Published by IOS Press. This is an Open Access article distributed under the terms of the Creative Commons Attribution-NonCommercial License (CC BY-NC 4.0).
} 
has deeper roots. We can trace these roots back to the High Middle Ages, when the European culture of eroticism began to flourish under the influence of Islamic art and literature, and also of the troubadours, who began to develop a new image of eroticism in their songs and poems. This image was first outlined in opposition to the institutional form of marriage, which Christianity had given to love (De Rougemont, 1983). An example of this is the chivalric romance/myth of Tristan and Isolde, which portrays an unfulfilled erotic love, full of obstacles and passion, that is willing to transgress any interdict and taboo, be it social or religious (De Rougemont, 1983). In Christian thinking, love was defined in terms of agape, which in the West led to the ideal of the Christian family. During the High Middle Ages, this position conflicted with the "heretical" idealization of the passionate erotic love of the troubadours and Arab artists (De Rougemont, 1983). However, beyond this short culturalhistorical foray, eroticism, within the limits of the philosophical construction of Western metaphysical heritage, has become more than simple sexual activity/sensuality specific to human nature. This is because, according to Plato, Eros is as much a 'transcendental signified' as it is a physical or emotional desire (Plato, 2005, 2008). In its common sense, however, eroticism involves conscious libidinal desire and physical pleasure, aspects that remove eroticism from the sexual activity of animals, which is based on an instinctual biological need to reproduce. For Plato, Eros, as a 'transcendental signified', is a way to contemplate the Beautiful in itself, and also a way of seeking the abstract and perfect ideas of 'beauty' and 'virtue', both in the realm of the body and of the soul - by privileging the 'intelligible world' to the detriment of the 'sensible/sensory world' (Plato, 2008). Hence, Plato's theory of eroticism fell within the hierarchical dialectic of the metaphysics of presence and idealism. Thus, in both the Symposium (Plato, 2008) and Phaedrus (Plato, 2005), Eros is rendered as a transcendental signified placed in the transcendental sphere of the 'theory of Ideas' and of love for knowledge, good, and beauty. Furthermore, in the Allegory of the Chariot (Plato, 2005) we are dealing with two metaphors, those of the white horse and the black horse, which we can easily attribute or expand to eroticism. The Platonic metaphor of the white horse symbolizes moderation and is characterized by the spirit of reason and temperance (Plato, 2005). This is because, in the metaphysics of presence, the 'soul' is seen as being superior to the body due to the fact that it is grounded in the 'intelligible world' of Ideas because it is immortal and predisposed to discover this 'intelligible world' through a process of transformation whose forces are represented by Eros (Plato, 2005, 2008). In addition to this, eroticism is defined in the Symposium as 'heavenly love', which, in Plato's philosophy, is also closely connected with the pederastic culture of ancient Greece and the ars erotica - "However, the Love which accompanies the heavenly goddess (and which does not descend from the female, but only from the male) is the love of boys (...) in that they do not love boys before the stage when their intelligence begins to develop, which is near the time when they begin to grow a beard" (Plato, 2008, 181c; 181d). On the other hand, the metaphor of the black horse symbolises the spirit driven by sensuality and the irrational desire of the body to lust, which is intrinsically connected to the sensible/sensory world (Plato, 2005, 2008). Here, Eros is placed within the sphere of sexual reproduction and of passionate carnal love, a position that is defined in the Symposium in terms of 'common love' - "The Love which belongs to Common Aphrodite is truly common and engages in his activity as opportunity offers. (... In the first place, men of this sort love women quite as much as boys, and secondly, their bodies more than their souls (...)" (Plato, 2008, 181b). However, even if some of Plato's reminiscences have remained rooted in the common sense of the European individual (in the sense of privileging the erotic feelings/desires, to the detriment of the physical lust), this does not mean that eroticism has a fixed and unchangeable structure. One argument regarding the removal in time of both pederastic and incestuous relations from Western culture, along with the continuing decrease in consanguineous marriages, became widespread during the Modern period (Bataille, 1986). This aspect emphasises that eroticism represents a fluid and rhizomatic materialization of human existence, linked not only to 
culture, society, religion, art, or philosophy but also to science and technology (in future years). This is also an argument for the continuous evolution, growth, and becoming of eroticism over time.

This paper therefore focuses on the paradigm shifts which have every chance of taking place at the erotic level as a result of future developments in technology. This aspect will probably bring, in the not-so-distant future, a set of changes, not only at the level of our daily interaction with technology, but also at the level of our erotic lives - through what Dubé and Anctil (2020) call artificial erotic agents (i.e., erobots). The concept of erobots is an umbrella term that encompasses virtual, embodied and/or augmented artificial erotic agents, sexbots, virtual or augmented erotic characters, erotic AI chatbots, erotic avatars, artificial partner applications etc. (Dubé \& Anctil, 2020). Even if nowadays products and services such as those offered by the Realbotix company (Harmony, the first weak AI female sexbot, Realbotix Harmony App, or Henry, the first weak AI male sexbot) are at an early stage of development, we must consider the possibility that in the coming years, erobots will increasingly make their presence felt in the erotic life of the individual - considering that, according to the futurist Ray Kurzweil, technology will grow exponentially in the coming decades (Kurzweil, 2005). Thus, perpetual progress in the field of technology will train human nature to accept and adapt also its intimate life to new conditions of existence - with machines (Dubé \& Anctil, 2020). However, this perspective already raises a series of questions regarding our future possible co-evolution and co-existence with these erobots, a perspective that may extend in the future beyond the human-biological loop. Thus, this new paradigm shift at the erotic level, from human to non-human (erobots), calls into question not only the traditional ontological background but also the cultural heritage of eroticism. I will analyze these aspects within the parameters of Graham Harman's $(2011,2017)$ object-oriented ontology (OOO), and Gilles Deleuze and Félix Guattari's (2000; 2005) deconstructivist approaches. Within the parameters of OOO, I will raise the following question: whether sexbots (as embodied artificial erotic agents) can have an erotic experience; either when the erotic interaction is between a human and a sexbot, or between sexbots? This is in order to show that in such a scenario we are moving beyond the anthropocentric resistance of human exceptionalism. In a Deleuze/Guattarian investigation I will analyze the mechanism underpinning the deterritorialization of eroticism (from human-natural limits), followed by its reterritorialization in the artificial dimension of technology (through erobots), a phenomenon that is displacing the conceptual order of eroticism. Thus, in the philosophical terms of Deleuze, deterritorialization is the fundamental precondition for the process of becoming - seen as a new way of being, a process of change, a generative force that is going beyond any fixed structure (Deleuze \& Guattari, 2005). Consequently, deterritorialization is a movement where, for instance, the natural and the cultural, the biological and the artificial, the human and the robot, are moving beyond the boundaries of essentialism, determinism or universally-valid norms, and where identities and bodies are deconstructed towards a rhizomatic system of becoming. Within these limits, a future presence of erobots in intimate human life accompanies the deterritorialization of eroticism from it's socio-cultural resistance - the system of the strata in Deleuze and Guattari's terms (2005); a process that may result in eroticism escaping from the boundaries of anthropocentrism by reterritorializing into the plane of consistency (which is immanent, heterogeneous and fluid), given by technology. The new assemblage resulting from this fusion between erobots and humans is not the loss of humanness but rather a new way of (trans)coding the erotic realm into a techno-erotic one.

\section{EROTICISM AND EROBOTS - AN OBJECT-ORIENTED ONTOLOGY APPROACH}

The immersion of the intimate sphere of the individual into technology, in the not too distant future, questions the reminiscences of the Western metaphysical legacy regarding the cultural dimension of 
eroticism, characterized by the romantic illusion of the autonomy of human erotic desire idealism, viewed by Georges Bataille (1986) as sensuality, transgression, romantic love, or as an experience merged into life itself. Due to these metaphysical attributes, eroticism is placed somewhere between the two Platonic metaphors of the "white horse" (where eroticism is seen as a "transcendental signified') and the "black horse" (which emphasizes the mutual interdependence of erotic lust and reproduction and is linked to the human physical and sensual realm) (Plato, 2008). This position emphasises the notion that these values regarding eroticism are located in an anthropocentric paradigm of thinking. This same paradigm has also made eroticism a human attribute, built around the idea of human complexity (characterized by the ontology of personhood). However, human nature has always been fascinated by technology, whether it is understood in its instrumentalist paradigm, as an extension of human capability, or in that of techne $\bar{e}$ as manufacturing/art (Heidegger, 1977). Thus, from the Pygmalion and Galatea myth, via Frankenstein's monster and up to the first examples of automata, humans have continually strived to build a connection with the non-human other through eroticism. However, these attempts have not always involved the subjectification of these non-human others and their inclusion within the ontological category of the ' $I$ '. This is because the inheritance of this anthropocentric thinking, specific to human-centric historicity, included the anthropomorphization of these non-human others rather than their acknowledgement in a post-dualist, post-anthropocentric, and non-hierarchical paradigm as subjects (Ferrando, 2019). However, this does not mean that in a post-dualist dialectic there is no dualism (Ferrando, 2019). Post-dualism means that we are dealing not with a vertical, hierarchical, and structural dualism, but with a fluid, non-hierarchical, rhizomatic, and transversal one (Ferrando, 2019). This is why erobots in a post-dualist paradigm are not the new "others" in a new form of discrimination or metaphysical idolatry, but real agents acknowledged in a post-anthropocentric thinking (Ferrando, 2019). Post-anthropocentrism doesn't mean the denial of all human attributes. Rather, it means the recognition of non-human ones - without seeing the human anymore as "the measure of all things" (Braidotti, 2013, p. 14). Also, the post-anthropocentric approach is a form of criticism regarding human specie supremacy. This means the decentering of the human from its ontological centrality, and the recognition of other non-human agents and entities as important as man (Braidotti, 2013; Ferrando, 2019). Thus, the possibility of an emergence in future years of a series of artificial erotic agents (erobots) will take us further away from the anthropocentric reminiscences built around eroticism. What we may identify in this scenario is an erosion of the anthropocentric dialectics of human exceptionalism, with there will be a diminishing of the boundaries between the human and the technological. This dynamic openness, according to which a plurality of perspectives can be accounted for, is opening into a 'plane of consistency' that dissolves 'the system of the strata' (Deleuze \& Guattari, 2005). This is an aspect that involves the process of 'becomingother' on the part of the human and that of 'becoming-human' (Ferrando, 2015, p. 276) on the part of the erobots. In this context, the system of the strata underlies the anthropocentric hierarchicaldualistic structures of the human-non-human/technological. However, this immersion into the plane of consistency will be due to the swift development of the adult erobots' industry, which will allow human agents to engage in erotic experiences in the absence of another human agent, i.e., beyond the metaphysical desire a human sees in the Other human agent, and that he/she hopes will bring self-sufficiency.

Moreover, in a Deleuzian deconstructivist interpretation, eroticism feeds the transgression of social constructivist norms regarding sexuality as well as the ontology of human personhood, the latter of which (in the limits of metaphysical thinking) is defined as one of the 'molar' socio-cultural codes of Western thought (Deleuze \& Guattari, 2000, 2005). This means we are about to leave behind this paradigm, in which we are dealing with the privileging of the human agent as an 'I', a paradigm that in the tradition of the metaphysics of presence has endowed human nature with self-consciousness, 
self-determination, rationality, and qualia. In such a paradigm, that of metaphysical interpretation, the erotic relationship between an erobot and a human agent is primarily one in which we have two distinct ontological categories. It is about an animated, rational and biological one (the human), and an inanimate and non-biological embodied or virtual one (the erobot). From this reductionist position it follows that non-human entities, lacking these human attributes, also lack personhood, situating them in the category of objects. In terms of the techno-erotic realm, which will include the presence of erobots, this metaphysical position and human-centric historicity will have to be overcome. The overcoming of this dualistic ontology aims to short-circuit the anthropocentric turning endowed with a set of exclusive qualities and entitlements found in romantic individualism, the slave of sameness, which evokes difference as disparagement, raising issues of power and exclusion. However, within the paradigm of OOO theory, we are dealing not only with the bracketing of this ontology of human personhood, which underlies the anthropocentric hegemony, but also with the release of objects from this hierarchical/dualistic structure and the recognition of their existence as independent of their simple interaction with the human subject. Thereby, in the Latourian actor-network theory, objects are defined as actants, such that humans and non-humans exist in an 'actor-networks' paradigm as a whole, where nature and culture are not separated but mixed and fluid (Latour, 2007). This is an aspect characterized by chains of translations that make the action possible (Latour, 2007). The objects in this interpretation are situated in an immanent post-dualistic, post-anthropocentric, rhizomatic, fluid, transversal, and relational dimension. This is a position that makes even the human agent an object among other objects, according to DeLanda's (2006) flat ontology. Thus, in the parameters of flat ontology, objects cannot be reduced to each other but neither can they be reduced to mere human experience (DeLanda, 2006). However, beyond the positions of Bruno Latour and Manuel DeLanda, Graham Harman's OOO theory is not flat because Harman does not deny the complexity of human experience (Harman, 2011, 2017). Instead, he seeks to move away from the onto-metaphysical tradition by paying as much attention to inanimate objects as animate ones. In so doing, he claims that the external world exists independently of human consciousness. Thus, he builds his theory around two categories of object: the real and the sensual (Harman, 2017). This is also the reason why, for Harman, objects correspond to real and sensual qualities (Harman, 2017). Thus, he emphasizes the fact that, in the relationship a man has with an object, there is a difference in degree and not in kind (Harman, 2017). Applied to the future existence of erobots, this means that an erobot as a sensual object is the erotic object as it appears to be represented in our phenomenal world - related to a posteriori knowledge in Kantian terms (1998) - alongside the whole set of various properties of our conscious experiences. This means that a sensual object is formed in the human mind through the senses that are responsible for our openness to the world. In this connection, an erobot as a sensual object is the result of the construction of sensual qualities. However, these sensual qualities are also the properties of the erobot, whether we are talking about their real or virtual representation (the seductive voice, the color/texture or smell of the skin, the voluptuous body shape, or provocative clothing). These are properties a human being can observe through the way he/she experiences/perceives an erobot in an X moment, in a real, virtual, or augmented realm. Moreover, these 'sensual objects' and their 'qualities' are affected by time, whose flow affects both conscious experience and the construction of 'sensual qualities' (Harman, 2011, 2017). This is why sensual objects and their qualities are constantly changing. However, if we are moving away from Harman's OOO and are situated within the limits of Daniel Dennett's (1998) philosophy of mind, we may observe that these various properties of our conscious experience form qualia. These represent our 'subjective', 'intrinsic', 'ineffable', and 'conscious experiences', which relate to the totality of the aspects and states accessible from a phenomenal point of view, at the level of our mental life (Dennett, 1998): and, by extension, those sensual objects and their qualities in Harman's terms (2017). Also, with respect to the theories of Ned Block (2002), this position places us within the parameters of what he calls phenomenal consciousness (P-consciousness). For Block, the 
properties of P-consciousness (accessed through the senses and conscious experiences) differ from the cognitive, intentional, representational, or functional properties of consciousness, which he calls access consciousness (A-consciousness) (Block, 2002) - the latter of which is responsible for our thoughts, beliefs, and desires. Also P-consciousness is closer to the idea of qualia in its narrow form of interpretation.

To understand this paradigm, let us imagine a sexbot (as a material embodied erobot), which is based on an AI system, in order to facilitate the interaction between human and sexbot. This system allows the sexbot to manifest certain human behaviors, such as having a discussion, emitting different sounds of arousal, blinking or detection of movement, which allows for the adjustment of vibration patterns based on human body movements. I propose to imagine further a situation in which, in the middle of sexual intercourse with such a sexbot, we suddenly notice the existence of a constant sound, in the form of a subtle moan that was present during the entire sexual act. According to an interpretation, close to Block's theories $(1995,2002)$, this arousal sound was present in our sexbot from the beginning (being provided in the AI system of the sexbot). However, this information did not pass through the direct rational filter of our action, until we noticed it in the "behaviour" of the sexbot, which changed as our interaction with the sexbot intensified. In such a situation, we are dealing with what Block $(1995,2002)$ calls the activation of A-consciousness regarding this AI system (being the basis of our sexbot), which causes us to turn our attention to the "behaviour" of the sexbot and to realize the fact that the subtle moan has been there since the beginning. In Heideggerian terms, this make the shift from the 'ready-to-hand' paradigm to that of the 'present-at-hand' regarding the sexbot, which is the basis for changing our comportament later (Heidegger, 1962). Thus, the fact that in this situation a sexbot appears in someone's conscious attention - as a result of his/her awareness regarding the sexbot as an object of his/her activity - this means that the sexbot is present-at-hand, i.e. it possesses real-life agency. As present-at-hand, the sexbot differs from anything that means a pre-determined set of functions integrated into its operation system, and becomes something that is perceived as being beyond its instrumentalist parameters (as ready-to-hand), namely as an actant in an actor-network convergence. In an OOO interpretation, this means that the sexbot is no longer within its instrumental limits, but within those of its creative (un)revealed potentialities through interaction, whence it follows that objects exist independently of human phenomenal consciousness. Such a position makes us see technology here rather as technē; that is to say, as a way of revealing, close to art and not to its mechanical usage related to its direct use, experienced by man (Heidegger, 1977). In this paradigm an erobot is no longer a simple object, or just something phenomenal for man, because in an $\mathrm{OOO}$ interpretation, human nature is no longer the center. By losing its centrality, man is becoming part of a rhizomatic co-evolution with technology. This post-anthropocentric becoming is also a way of understanding that eroticism is part of technological evolution, where technology can reveal the presence of an inwardness of erobots (even if they are never fully opened to us). That is to say, this inwardness represents the fact that for both speculative and practical reasons man can't fully penetrate the realm of erobots (Harman, 2011, 2017).

However, beyond this paradigm, these erobots may also be interpreted as real objects, in Harman's (2017) theory, especially if we are dealing with the material embodiment of such an object, as in the case of a sexbot. Also, in the OOO limits, the non-material embodiment is also considered, when we are dealing with the digital/virtual realm, such as avatars or virtual/augmented reality erobots. But let us return to our scenario regarding the sexbot. If a sexbot becomes a physical entity in the world, its real qualities are those defining characteristics that make the object what it is. This means in anthropocentric general terms, a sex companion whose sexual availability is permanent. However, Harman (2017) emphasize somehow that we can never have access to the real object 'in itself'; that is, we cannot have access to the noumenal world and to a priori knowledge (Kant, 1998). This means that 
the inwardness of objects escapes our grasp. Hence, these real properties of an erobot create an ontological void. This is a consequence of the fact that what man considers to be real is only a construction of his perceptual and sensory field, to which he has access especially at the phenomenal level - the ontological void being situated in between these noumenal and phenomenal worlds, or between our P-consciousness and A-consciousness. This is why we never touch 'real objects', but always 'sensual objects' and their qualities (Harman, 2011). However, the erosion of the boundaries between the human and the technological will result in the future in an onto-epistemological implosion between what we call 'real' and 'sensual' (Harman, 2011). This is due to the fact that in a post-anthropocentric paradigm, erobots no longer represent simple ready-to-hand entities for the human agent, as part of his actions or inter-actions; they are rather 'present-at-hand' (Heidegger, 1962) entities, namely agents of everyday perception in an actor-network convergence. Bun the anthropocentric paradigm tells us that even if we have a P-consciousness of the present sexbot, in order for it to become present-at-hand, we also need the intervention of A-consciousness, which is the non-phenomenal category of our consciousness. This encapsulates the paradigm of knowledge and representation used in the direct rational control of all our thoughts and actions (Block, 1995), a position that still seems to place us in a hierarchical binary dialectic of anthropocentric taxonomy, because of this conflict between the human 'I' (as consciousness/reason) and the third person perspective of non-human objects. Nevertheless, in a Latourian interpretation, such a position must be left behind, in order to live in a nature-culture hybrid realm where the borders between the ontic and the ontological are blurred (Latour, 2007).

In this respect, one hypothesis that is displacing the conceptual order of eroticism (built around human nature), is relevant when dealing with sexual intercourse between two sexbots, the question that arises here being: how do objects experience each other? In this case, how does a sexbot (as a representation of a sensual object for humans) access reality and the sensual properties of another real object (another sexbot) in this new techno-erotic realm. For Harman $(2011,2017)$, objects do interact and relate to each other, even if at a wholly different level from our phenomenal dimension (which implies the presence of qualia and of that of the A/P-consciousness). In this point, Harman's position overcome not only Block's $(1995,2002)$ theories, but also the transcendental idealism of Kant (1998), according to which reality is based solely on the human-world relationship. Thus, Harman (2011), in his relationism theory, claims that nothing is real unless it has a certain effect on something, which means that the existence of an object consists both of its relationality with other objects and with itself, or as a fluid 'network' in a Latourian sense (Latour, 2007). It follows that the way a sexbot accesses reality, in this techno-erotic realm, is a result of its interaction with other objects, both with other erobots and also with itself. Within these limits, a sexbot can be perceived as a kind of representation of a sensual object. It is not, however, the sensual object seen in the phenomenal parameters, understood from the way that human consciousness accesses the physical reality (through P-/ consciousness), but the sensual object that results from the way in which the operating programs, based on an AI or machine learning system, which are linked to a cloud-based algorithm, access reality, both by 'relating' to each other and also within the limits of their own autonomy (in the sense that for Harman (2017), objects have their own autonomy). Thus, a sexbot can take the dimension of a sensual object for another sexbot when the programs running on both sexbots are able to access each other; thus, the sensual qualities can be read/accessed by each program in each part. Hence, erotic activity between two sexbots can be an event in which one object, the sexbot, accesses another sexbot. What a human agent perceive in this techno-erotic event (as observing consciousness) is practically a representation of the sensual properties of the two sexbots, when the programs upon which they are based are turned on and are exchanging information (relates). However, for humans this situation is an indirect erotic contact between sexbots. In this human-centric paradigm, the dimensions of the sensual object and 
their sensual qualities are bracketed, because no sexbot interacts, for example, with the color, texture, skin odor or voluptuous shapes of the other sexbot's body, which are visible/accessible through P-consciousness. Bun in an OOO interpretation, sexbots do not touch each other as a whole, or in part, but only as an element of relationality. This translates the way that objects 'withdrawal' into an ontological void renders them inaccessible to the human mind (Harman, 2017). This aspect does not mean, however, that these sexbots do not relate to each other at all, in this techno-erotic realm. They are able to touch each other at a certain level that remains hidden from human perception. As objects always have the ability to 'withdraw' to their own inner ontological realm, they can never be exhausted by any of their 'real' or 'sensual' qualities (Harman, 2017). This is why it is not possible to know the erotic experience of these sexbots, because this remains inaccessible to humans, because humans have only partial access to erobots (even when in erotic contact with them) and the erobots withdraw from direct human access. It follows that (beyond human observational consciousness), an erotic relation has been formed between the two sexbots, and each of them can exist as a sensual object for the other. Even if this may not take a P-/A-conscious dimension, for erobots, it can take other forms/dimensions to which we do not have access. Moreover, this means that any non-human object can be seen at least as "an 'I' in the sense of having a definite inwardness that can never fully be grasped" (Harman, 2017, p. 70). This is not in the sense that we may believe that an erobot would have some sort of human consciousness (like the P-/A-consciousness), but for the simple fact that it is (Harman, 2017). Furthermore, their simple existence, in this techno-erotic realm, transforms them into a mechanism of the deterritorialization of eroticism from its anthropocentric limits.

\section{THE RISE OF EROBOTS AND THE DETERRITORIALIZATION OF EROTICISM}

In the above scenarios involving sexbots - seen as integral elements of what Dubé and Anctil (2020) generically call erobots - I tried to analyze only a few perspectives, within the limits of OOO, regarding how eroticism will be perceived/consumed in the future. But now I am making the shift from this OOO interpretation to that of Deleuze and Guattari's deconstructivist approach, in order to show that in this future techno-erotic realm, when erobots will probably play a central role in human intimacy, eroticism will be subjected to a paradigm shift. Thus, this new form of eroticism, which will occurr on the horizons of technology, will lead to the 'deterritorialization' of eroticism from the vertical paradigm of onto-metaphysical heritage thinking and its 'reterritorialization' in the 'rhizomatic' and 'transversal' dimension of the 'becoming' of the human (Deleuze \& Guattari, 2000, 2005). This describes the process of the human 'becoming-other' in order to form an emergent system or 'assemblages' in the non-human realm of 'becoming-human' of the erobots (Ferrando, 2015). However, this doesn't means the anthropomorphization of erobots, or the de-humanization of humans, but rather an emergent process of becoming, which is relational, external, collective and convergent. This also should be understood as a process that implies the deterritorialization of the symbolic heritage of eroticism, a mechanism that will attract the flourishing of an infinite abundance of differences, which will no longer be subjected to any a priori transcendental categories, but rather will be untied to form a multiplicity of contingent, dynamic and intensive connections between human beings and erobots. In Deleuzo/Guattarian terms, we are talking about the 'territorialization' of eroticism through a process that involves a continual 'deterritorialization', namely, a rupture from the inheritance of socio-cultural codes regarding human erotico-sexual habits (Deleuze \& Guattari, 2005). The reterritorialization of eroticism into the new territory of future technologies is the result of the formation of a series of new techno-erotic codes. These codes will be given by erobots (such as virtual seduction and sexual stimulation/simulation, human-machine intimacy or haptic technology, under the auspices of erotic avatars, 
3D erotic holograms, immaterial operating systems, sexbots, etc.). The same codes reinscribe eroticism and sexuality in terms of technology, a process that confers a technological value to eroticism and sexuality (technology interpreted here in Heideggerian terms as techne (Heidegger, 1977), and not within instrumentalist limits). This means that eroticism and sexuality will be no longer a form of scientia sexualis, nor a form of ars erotica (Foucault, 1990), or even a simple way of transgressing the taboo interdicts (in Bataille's (1986) thinking), but rather a way through which technology reveals its yet unrealized potentialities, displacing the conceptual order of eroticism from the social system of the strata (Deleuze \& Guattari, 2005). This denotes a fluid transformation of erotic forces, namely a virtual state of creative becoming in the techno-erotic territory (given by artificial intelligence, machine learning systems linked to cloud-based algorithms, virtual reality, augmented reality, or by the not-too-distant future of extended reality). It will mean that eroticism will no be longer situated within anthropocentric structural parameters which we may identify in the so-called vanity of romantic idealism, but within the post-anthropocentric one, namely in multiple, transversal, fluid, and rhizomatic parameters which include erobots. However, this exhaustion of anthropocentric eroticism, viewed within the cultural limits of the strata, does not necessarily represent a crisis of human creative erotic potentialities. It is instead a process that involves a twist and a dissolution of the social constructivist norms and taboos regarding what sexuality (one of the main ingredients in eroticism), means in 'the system of the strata' situated under the human essentialist loop (Deleuze \& Guattari, 2005). Specifically, within the 'molar' and 'macropolitical' power relations situated within the framework of sexual polarizations, biological determinism and the gender-hierarchical dichotomy paradigm (Deleuze \& Guattari, 2005). This also created the prototype of Western male exceptionalism, where the entire sexual dialectic was constructed around a fixed structure, namely that of the masculine bias subjectivity (the phallocentric one). Also, within the limits of essentialism or human biological determinism, sex is a biological essence (man-woman), a position that resulted in this standardization of sexuality in the equation of the human heterosexual relations of the macropolitics of the majority. This macropolitics operates in hierarchical relations, universally-valid norms and on predetermined epistemological bases that fuel power relations (Deleuze \& Guattari, 2005). However, in this future scenario - the immersion of erobots within the intimate life of the individual - sexuality evades both this biological determinism and the molar paradigm (given by the organised, well-defined and preformed social groups and collective categories). This will bring the activation of the plane of consistency through a reformation of systems of the strata - that will take place through the dissolution of homogenous dominant practices (biological/heterosexual) from inside of the socio-cultural macro-policies of sexuality/eroticism. It means technology will deterritorializes both this reproductive naturalism (with artificial wombs, insemination in vitro, etc.) as well as the social constructivism of the macropolitical power game of human heteronormativity and anthropocentrism (through the erobots), then reterritorializes them into the micro-political events and molecular becomings of trans-species sexuality and post-gender territory. This molecular movement and micro-political events refers to the dissolution of strict binaries, dualistic models and hierarchical approaches - being patchy, dynamic, rhizomatic and fragmented - operating beyond the paternalistic organization of society (Deleuze \& Guattari, 2005). These processes are causing sexuality to move beyond gender-dichotomy, biological limitations, and anthropocentrism toward a "dispersed, not binary, multiple, not dualistic, interconnected, not dialectical and in a constant flux, not fixed" way of becoming-other (Braidotti \& Dolphijn, 2014, p. 31). This way of 'becoming-other' of the human is also 'nomadic', anti-essentialist, and $a$-subjective; it is a process that goes beyond the notion of individuality and through a 'trans-personal' mode of being (Braidotti \& Dolphijn, 2014, pp. 13-37). In a Deleuzo/Guattarian interpretation, this means that we will no longer be dealing with only two biological sexes (namely, heterosexual genital sexuality), responsible within essentialist limits for the perpetuation of the species, but with an unlimited number of sexes $-n$ sexes and sexual potentialities (Deleuze \& Guattari, 2005). In this respect, sexuality as a 
metanarrative of human species perpetuation is short-circuited by the deterritorialization of eroticism, from its own socially constructed limits (found in its anthropomorphic, phallocentric, and metaphysical representations), and reterritorialized in the field of technology and that of multi-sexual developments. This will lead to the creation of an erotic assemblage of the 'body without organs', whose multiple entries undermine the entire 'molar' flow of sexuality, moving in a fluid direction towards 'molecular' convergences between countless sexes (human, non-human/non-biological, virtual, artificial, etc.) as mechanisms of 'becomings' within human techno-eroticism (Deleuze \& Guattari, 2000; 2005). Moreover, these mechanisms will cause eroticism to release a creative force that results in the fragmentation and undermining of essentialist categories, in addition to the recognition of asymmetries/differences, as embodied and embedded in human/non-human existence. It is a phenomenon that will go beyond the exclusive stratification of Being(s), being situated in the framework of a positive dialectic which emphasizes an immanent version of relationism and pluralism, on a molecular level, in the field of the body without organs. Thus, the 'body without organs' is the space that activates the realm of the 'molecular sex', through erobots, and where the territorialization of eroticism will take place in the 'virtual plane of consistency', where bodies (whether biological or non-biological, natural or artificial) will form in different 'assemblages', namely in emerging units of 'consistency' (i.e. biotechno-fusion) (Deleuze \& Guattari, 2000; 2005). Thus, the body without organs is an open system, a nomadic becoming (Deleuze \& Guattari, 2005) of the individual techno-eroticism that extends beyond the bordered and conventional plateau of human strata sexuality, toward a symbiotic emergent unit of man-machine eroticism. This process will become visible in this transition from social constructivist norms and taboos (specific to the eroticism strata) to the plane of consistency of erobots. This concerns a shift between cultural and structural differences, ontological categories, or between organic and inorganic. It also implies the overcoming of the dualistic frame of man-machine/technology interaction, towards a rhizomatic co-evolution and co-existence with erobots.

Thus, the territorialization of eroticism, within the limits of this emergent ontology of man-technology fusion, attracts the immanentization and demystification of Eros. This is the result of its deterritorialization, from the paradigm of the absolute and irreducible transcendental signified, and its reterritorialization in the immanent, 'molecular' and 'micro-politics' of affects as 'events' (Deleuze \& Guattari, 2005). This aspect is part of the process of the becoming-other of the human, which occurs through the trans-species sexualization of intimacy. Thus, this future scenario of experiencing eroticism through erobots, will be about to become an integral part of the process of becoming-molecular/minoritarian of the human, which removes sexuality and eroticism from the limitations of the essentialist and sociocultural heritage by engaging the forces of deterritorialization. This immanent process of co-creating eroticism into new shapes that involve the technological realm of erobots involves a shift from the transcendental field to that of the immanent plateau. It is a phenomenon that extends beyond any ideological, political, cultural or universally-valid scientific concept for regarding eroticism, and beyond any pre-determined matrix of possibilities and taxonomies. It is rather a praxis or the 'lines of flight' regarding what it means to 'affect and be affected' by technology - as the two ingredients of the future techno-erotic 'event', in Deleuzo/Guattarian terms (2005). At the same time, this paradigm of affects and events, refers to the rhizomatic embodied and embedded experiences, and sometimes emotions, that take place when humans are in contact with an erobot. This initiates an ongoing, ever-changing process of reshaping eroticism within its anthropocentric cultural legacy and its sites of resistance, found under the auspices of sexual taboos, biological essentialism, and in the dialectic of the strata. As such, eroticism will no longer be a simple way of transgressing these interdicts but a new immanent realm of affects and events that implies an openness to the technological world. In a Deleuzo/Guattarian (2005) interpretation this will occur through a set of 'transversal polyvalent cuts' that unleash a mutual inclusion in the erotic 'event' - of the human/technological or non-biological elements - that 
within the limits of the Western philosophical tradition were separated from it, and also from each other, by the metaphysics of presence discourse and a subject-object dichotomy. This new set of relationships also emphasizes another paradigm shift at an erotic level, found under the human-erobots micro-events process of becoming and differentiation. It concerns the process that will reshape our cultural attitudes, relationships and existence, which will be defined by the co-existence of multiple technological elements in the erotic realm. This techno-eroticism (via erobots) will reshape not only human erotic behaviour but also the perception of this behaviour in the direction of a greater plurality and multiple perspectives. This is part of the deterritorialization of human erotic emotions - accumulated in memory, habits, or desires - and their reterritorialization in the paradigm of technology, as the future co-presence of all erotic potentialities, found under the multi-layered and transversal way of connecting to this techno-erotic realm. In this regard, erobots short-circuit anthropocentric grounding through the decentralization of the human, and the de-instrumentalization of technology as a simple readiness-to-hand. This can be encountered, for the moment, both in the case of erotic AI chatbots, and in the case of sexbots or virtual or augmented erotic characters, such as those created by Realbotix's Harmony AI program. Thus, we can refer to a technological or virtual embodiment as a process of becoming-human. Nowadays, the identification of embodiment in the case of Harmony sexbots, avatars, apps (also found in virtual or augmented reality) is an important element in determining what the process of deterritorialization of eroticism means with respect to erobots, because it calls into question the problem of the body and the 'ability to affect or be affected' (Spinoza, 2018; Massumi, 2002). In a Spinozist approach, this 'power to affect' and 'be affected' is specific to the way in which humans are open to the world; as complex entities defined as being "the embodiment of the mind and the embrainment of the body" (Braidotti, 2013, p. 86). This means that human nature, which possesses a body, is also represented/seen as being a body. However, this position will be recodified by the fluidity of the body without organs, in the future. Because in the techno-erotic realm, we will move through eroticism, not within the limits of the Cartesian dualism paradigm or within socio-cultural or political normativities (when experiencing a techno-erotic event), but rather in a continuing process of actualizing certain potentialities and creativities - grounded in an immanent, post-dualist and multi-directional relationality revealed by this erobotic event. Here, techno-eroticism is nothing more than the fluid and dynamic category of difference, actualized through our future multi-faceted relational bonds with erobots. It is also the virtual force that creates the dynamic web of becoming of the future individual's intimate life, whereby the mode of 'becoming-human' of erobots and 'becoming-other' of humans does not represent, as I mentioned, the anthropomorphization of erobots, or that of de-humanizing humans, within the realm of this techno-eroticism (Ferrando, 2015). On the contrary, it reveals an entire set of unexplored creativities through the formation of new alliances opposed to the system of strata. In such a system, we can talabout a 'mimesis' in which human eroticism 'deterritorializes' by forming an image of eroticism (a techno-erotic one), and erobots then 'reterritorialize' on that image by copying/imitating the human eroticism (Deleuze \& Guattari, 2005). Even if, at first glance, this seems to be a heterogeneous and rhizomatic process, it is still located in the strata paradigm. To move in the 'plane of consistency' of the 'becoming-other' of the human and the 'becoming-human' of the erobots, an approach to a 'rhizomatic' existence is required in which there is more than a simple mimesis (Deleuze \& Guattari, 2005). It is a form of cartography and the fluid potentialities that are emerging from this future techno-eroticism. It is therefore about capturing the techno-erotic code, an aspect that does not mean translating one code into another (of the human into the technological and vice versa) but the rhizomatic process of transcoding it. It is a shift that takes place in the plane of immanence, in which the constituting of the rhizomatic plane of eroticism is fluid, multiple, and interchangeable, with $n$ dimensions, without a subject or an object but "neither beginning nor end, but always a middle (milieu) from which it grows" and which it surpasses in endless forms and 'events' (Deleuze \& Guattari 2005, p. 21). This leads not only to a dissolution of 
anthropocentrism and to a fluidization of the boundaries between human and technological - through our future co-existence/evolution with erobots - but also to the rethinking of eroticism as an open system, a productive connection that creates new heterogenous assemblages, namely emerging unities of consistency.

\section{CONCLUSIONS}

The deterritorialization of eroticism involves the fluidization of several 'plateaus' from the sociocultural to the ontological, technological, personal, or phenomenal. These 'lines of flight' and rupture that the future presence of erobots traces in the techno-erotic realm of the individual are rhizomatic assemblages that establish immanent and transversal connections between certain multiplicities (human, social, technological, erotic, sexual etc., with their particles of becoming). In this paradigm of post-dualism, we move beyond any hierarchical dualism between subject and object, beyond any axiological dualism between sexuality and eroticism, and beyond any onto-metaphysical dualism between man and technology. Within these limits, the immersion in the parameters of the $\mathrm{OOO}$ - where human nature is decentralized from the onto-metaphysical dialectic of anthropocentric autonomy eroticism is no longer just a human prerogative but also a non-human one. In this respect, objects, such as those found under the auspices of erobots, overcome their purely instrumentalist parameters (as simple objects intended to satisfy human libidinal pleasure) and become entities with real autonomy (beyond human observational consciousness). They exist and relate to us, and also to each other, in an ontological void, inaccessible to the human mind, in the sense that we do not have direct access to the erobots-in-themselves. This is a process that will place us outside the transcendental faculty of judgment of the onto-metaphysical tradition - specific to the hierarchical dialectics of the metaphysics of presence; namely, in that of the multiperspectival relationalities, immanent and polyvalent assemblages with technology, in which erobots are viewed as the rhizomatic plane of consistency of our future techno-erotic becoming.

\section{REFERENCES}

Bataille, G. (1986). Death and Sensuality: A Study of Eroticism and the Taboo. San Francisco: City Lights Books.

Block, N. (1995). On a confusion about a function of consciousness. Behavioral and Brain Sciences, 18(2), 227-247. doi:10.1017/S0140525X00038188.

Block, N. (2002). Troubles with functionalism. In D. Chalmeras (Ed.), Philosophy of Mind: Classical and Contemporary Readings (pp. 94-99). Oxford: Oxford University Press.

Braidotti, R. (2013). The Posthuman. Cambridge: Polity Press.

Braidotti, R. \& Dolphijn, R. (2014). Introduction: Deleuze's philosophy and the art of life or: What does Pussy Riot know?. In R. Braidotti and R. Dolphijn (Eds.), This Deleuzian Century (pp. 13-37). Boston: Brill Rodopi. doi:10.1163/9789401211987_002.

De Rougemont, D. (1983). Love in the Western World. Princeton: Princeton University Press.

DeLanda, M. (2006). A New Philosophy of Society: Assemblage Theory and Social Complexity. London: Continuum.

Deleuze, G. \& Guattari, F. (2000). Anti-Oedip: Capitalism and Schizophrenia. Minneapolis: University of Minnesota Press. (R. Hurley, M. Seem \& H. R. Lane, Trans.). 
Deleuze, G. \& Guattari, F. (2005). A Thousand Plateaus: Capitalism and Schizophrenia. Minneapolis: University of Minnesota Press. (B. Massumi, Trans.).

Dennett, D.C. (1998). Quining qualia. In A.J. Marcel and E. Bisiach (Eds.), Consciousness in Contemporary Science (pp. 381-414). New York: Oxford University Press.

Dubé, S. \& Anctil, D. (2020). Foundations of erobotics. In International Journal of Social Robotics (pp. 1-29). Springer. doi:10.1007/s12369-020-00706-0.

Ferrando, F. (2019). Philosophical Posthumanism. New York: Bloomsbury.

Ferrando, F. (2015). Of posthuman born: Gender, utopia and the posthuman in films and TV. In M. Hauskeller et al. (Eds.), The Palgrave Handbook of Posthumanism in Film and Television (pp. 269-279). New York: Palgrave Macmillan. doi:10.1057/9781137430328_27.

Foucault, M. (1990). The History of Sexuality, Vol. 1: An Introduction. New York: Vintage Books.

Harman, G. (2011). The Quadruple Object. UK: Zero Books.

Harman, G. (2017). Object-Oriented Ontology: A New Theory of Everything. UK: Penguin Random House.

Heidegger, M. (1962). Being and Time. Cambridge: Blackwell Publishers Ltd.

Heidegger, M. (1977). The Question Concerning Technology and Other Essays. Garland: London \& New York.

Kant, I. (1998). Critique of Pure Reason. Cambridge: Cambridge University Press.

Kurzweil, R. (2005). The Singularity Is Near. New York: Viking Penguin.

Latour, B. (2007). Reassembling the Social: An Introduction to Actor-Network-Theory. Oxford: Oxford University Press.

Massumi, B. (2002). Parables for the Virtual: Movement, Affect, Sensation. USA: Duke University Press Books.

Plato (2005). Phaedrus. London: Penguin Classics. (C. Rowe, Trans.).

Plato (2008). Symposium. New York: Cambridge University Press. (M. C. Howatson ed. \& trans.)

Spinoza, B. (2018). Ethics. Proved in Geometrical Order. Cambridge: Cambridge University Press. 